\title{
POTENCIAL DE RIZOBACTÉRIAS NO CONTROLE DE Fusarium solani (Mart.) Sacc. EM PEPINO (Cucumis sativum L.).
}

\author{
I. S. DE MELO; P. J. VALARINI \\ CNPMAEMBRAPA - C.P. 69 - CEP: 13820-000 - Jaguariúna, SP.
}

\begin{abstract}
RESUMO: Rizobactérias, isoladas da rizosfera de diferentes hospedeiros foram selecionadas in vitro quanto ao antagonismo contra Fusarium solani agente causal da podridăo radlcular. In vitro, foram selecionadas 18 bactérias isoladas da rizosfera de plantas sadias de pepino e, destas, somente três foram eficientes em inibir consideravelmente o crescimento micelial do patógeno. Dois isolados de Bacillus subtilis e dols de Pseudomonas sp., antagônicos a outros fungos fitopatogênicos foram inclúdos nos testes, os quais mostraram-se capazes de antagonizar $F$. solani. Em condiçöes de casa-de-vegetaçāo, $B$. subtilis, linhagem OG, controlou totalmente o patógeno em todos os ensaios realizados. Promoçảo do crescimento de plantas fol verincada pela inoculaçao com linhagens 0G (B. subtilis), St. Barb. e CBPN (Pseudomonas sp).
\end{abstract}

Descritores:Rizobactérias, hiocontrole, Fusarium solani, pepino

\section{POTENTIAL OF RHIZOBACTERIA IN THE CONTROL OF Fusarium solani} (Mart.) Sacc. IN CUCUMBER (Cucumis sativum L.).

\begin{abstract}
Rhizobacteria, isolated from the rhizosphere of different hosts were selected in vitro, based on the antagonism against Fusarium solani, agent of rot rot. In virro, 18 bacterias were selected from rhizosphere of healthy plants of cucumber and, from those, only three were efficient in inhibiting the micelial growth of the pathogen. In these tests two isolates of Bacillus subtilis (OG and SG), and two of Pseudomonas (CBPN and St. Barb.), antagonistic to some pathogenic fungi, were included. These isolates abo inhibited the growth of $F$. solani. The isolate $0 G$ of $B$. subtilis reduced significantly the root rot of cucumber. Beneficial effects were obtained with the isolates St. Barb., OG and CBPN in relation to plant growth.
\end{abstract}

Key words: Rhizobacteria, biocontrol, Fusarium solanim, cucumber

\section{INTRODUÇÃO}

A podridão radicular de pepino (Cucumis sativus L.) por Fusarium solani (Mart.) Sacc. é, juntamente com a murcha causada por $F$ oxysporum, doença que pode provocar perdas significativas em cultivos sob estufas no Estado de São Paulo. O monocultivo, nestas condiçzes, resulta em alta densidade de inóculo do patógeno, o que acarreta danos severos e morte de plantas. Nestas condições, a prática usual de controle da podridão radicular tem sido através da enxertia em moranga (Cucurbita maxima Duch.) que tem se mostrado mais resistente ao patógeno.

Várias evidências têm suportado a intervenção de microrganismos da rizosfera como agentes protetores contra patógenos do solo (MELO, 1991; ROBBS, 1991). O comportamento destes antagonistas é estabelecido através de inoculação junto ou não com o patógeno. Em muitos casos, a correlação tem sido estabelecida entre antagonismo in vitro e proteção ao nivel de campo (BROADBENT et al., 1971; NAIR \& FAHY, 1972; FILIPPI et al., 1987; MICHAEL \& NELSON, 1972). Microrganismos antagônicos têm sido avaliados como um meio de controlar podridoes radiculares causadas por Fusarium sp. em cravo (ALDRICH \& BAKER, 1970; KOTHS \& GUNNER, 1967; MICHAEL \& NELSON, 1972), trigo (STEVENSON, 1956), soja (CUBETA et al., 1985), cebola (UTKHEDE \& RAHE, 1983).

Nesse sentido, aventou-se a possibilidade de utilização de bactérias antagônicas a $F$. solani na cultura de pepino dado ao potencial destas de colonizarem o sistema radicular e atuarem como uma barreira à penetração do patógeno. Este trabalho teve por objetivo mostrar o potencial de bactérias para tratamento de mudas de pepino para controle da podridão de raízes de pepino. 


\section{MATERIAIS E METODOS}

Isolamento de Bactérias Antagônicas a Fusarium solani (Mart.) Sacc: Amostras de solo foram coletadas a partir de solo aderido às raizes provenientes de plantas de pepino sadias desenvolvidas numa mistura de esterco de galinha e solo. Um grama de solo foi colocado em tubos de ensaio contendo $9 \mathrm{ml}$ de solução salina $(0,85 \% \mathrm{NaCl})$, agitados por 1 minuto em agitador Vortex e por 20 segundos em ultra-som a fim de promover a liberação e homogeneização da suspensão bacteriana. Diluições em série foram feitas até $10^{-7}$ e alíquotas de $0,1 \mathrm{ml}$ das três últimas diluições plaqueadas em meio King's B. As culturas foram incubadas a $28^{\circ} \mathrm{C}$ por 5 dias quando procedeu-se a pulverização de uma suspensão de conídios de F. solani $\left(10^{7}\right.$ conídios $\left./ \mathrm{ml}\right)$ sobre a superficie do meio onde as colônias de bactérias se desenvolviam. As culturas 073 foram incubadas a $28^{\circ} \mathrm{C}$ por mais sete dias quando foram identificadas colônias da bactéria manifestando zonas de inibição ao fungo.

Dois isolados de Bacillus subtilis e dois de Pseudomonas sp. obtidos da rizosfera de plantas de feijoeiro e cenoura respectivamente e antagônicas ao $F$. solani, foram incluidas nos ensaios.

Teste de Antagonismo in vitro: Isolados bacterianos que produziram zonas de inibição foram repicados, purificados em meio nutriente ágar (NA) e armazenados em NA a $5^{\circ} \mathrm{C}$. Sete isolados foram selecionados e testados individualmente em meio BDA, colocando-se um disco de agar de $0,5 \mathrm{~cm}$ com crescimento abundante de Fusarium a $1,5 \mathrm{~cm}$ da borda da placa e na outra extremidade uma estria da bactéria selecionada. Foram feitas quatro repetições por tratamento. Após 10 dias de incubação a redução do crescimento micelial foi medida. Este teste foi repetido três vezes com as bactérias que mostraram efeito inibitório.

Teste de Antagonismo in vivo: Uma mistura de solo de floresta e esterco de galinha na proporção 4:1 foi esterilizado $\mathrm{em}$ autoclave e deixado em repouso por três dias antes do plantio. As bactérias utilizadas neste ensaio foram selecionadas frente aos resultados do teste de antagonismo in vitro, quais sejam OG, CBPN, Santa Bárbara e 5 PEP. Cada linhagem de bactéria foi cultivada $\mathrm{em}$ meio nutrienteágar por 24 horas. Células bacterianas de uma placa foram suspendidas em uma solução de carboximetil celulose $1,5 \%$ onde as sementes de pepino foram imersas por $30 \mathrm{~min}$. As sementes foram deixadas para secar a temperatura ambiente $\left(25^{\circ} \mathrm{C}\right.$ por duas horas) e semeadas em solo artificialmente infestado com o patógeno. Como testemunha, utilizou-se solo sem a infestação do fungo e sementes tratadas com fungicida (benomil).

A infestação do solo com F. solani foi realizada através de um triturado de milho pipoca colonizado por 07 dias, na quantidade de $20 \mathrm{~g} / \mathrm{kg}$ de solo.

Adotou-se um delineamento $\mathrm{em}$ blocos casualizados com três repetições sendo 10 plantas por repetição.

A reação de plantas ao patógeno foi feita pela avaliação do número de plantas mortas. Quando não se verificava estes sintomas, as plantas eram arrancadas e avaliadas quanto à podridão no sistema radicular.

O mesmo procedimento foi realizado, mudando-se o modo de inoculação das bactérias. Neste experimento, as raizes de plantas de pepino do cultivar Aodai com 18 dias de idade foram imersas numa suspensão de células bacterianas na concentração de $10^{8} \mathrm{ufc} / \mathrm{ml}$ e imediatamente plantadas em solo infestado artificialmente com o patógeno.

Tratamentos-controle somente com as rizobactérias foram feitos a fim de avaliar-se os efeitos das mesmas na promoção de crescimento de plantas de pepino. Avaliou-se o peso seco da parte aérea e das raízes de plantas de pepino com 45 dias de idade, inoculadas com as bactérias e plantadas em solo esterilizado.

\section{RESULTADOS E DISCUSSÃO}

Teste de Antagonismo in vitro: De dezoito bactérias isoladas da rizosfera de pepino que mostraram antagonismo a $F$ solani através de observações de zonas de inibição foram selecionadas apenas três, 4 PEP, 5 PEP e 6 PEP, para os testes subsequentes. Neste teste, foram incluídos dois isolados de Bacillus subtilis (OG e 5G) que têm se mostrado antagônicos a Fusarium solani e dois de Pseudomonas spp.

Todas estas bactérias inibiram significativamente o crescimento micelial de F. solani (TABELA 1). Verificou-se que as bactérias introduzidas (CBPN, OG, St. Bárb. e 5G), não isoladas da rizosfera de pepino, mostraram uma atividade antagônica, in vitro superior, quando comparadas com os isolados $4 \mathrm{PEP}$, 5 PEP e 6 PEP da rizosfera de pepino. Esses resultados indicam que as rizobactérias isoladas de diferentes culturas não apresentaram especificidade de ação, o que permite a sua utilização para diferentes sistemas planta-patógeno. 
TABELA 1. Inibição do crescimento micelial de Fusarium solani causada por bactérias isoladas do rizoplano de diferentes hospedeiros.

\begin{tabular}{lcc}
\hline \hline Tratamento & Crescimento micelial (cm) & $\begin{array}{l}\text { Inibição (\%) } \\
\text { do crescimento } \\
\text { micelial }\end{array}$ \\
\hline Controle & $8,00 \mathrm{a}$ & 0,0 \\
4-PEP & $5,03 \mathrm{~b}$ & 37,125 \\
6-PEP & $4,66 \mathrm{~b}$ & 41,750 \\
5-PEP & $3,76 \mathrm{c}$ & 53,000 \\
SG (Bacillus subtilis) & $3,73 \mathrm{c}$ & 53,375 \\
St BARB (Pseudomonas putida) & $2,66 \mathrm{~d}$ & 66,750 \\
OG (Bacillus subtilis) & $2,26 \mathrm{~d} \mathrm{e}$ & 71,750 \\
CBPN (Pseudomonas sp.) & $1,76 \mathrm{e}$ & 78,000 \\
\hline CV (\%) & 6,71 & \\
\hline \hline
\end{tabular}

' Média de três repetições. Médias seguidas da mesma letra não diferem entre si pelo teste de Tukey a $5 \%$

TABELA 2. Efeito de Rizobactérias no controle de Fusarium solani em pepino. Dados expressos em porcentagens de mortalidade de plantas.

\begin{tabular}{llc}
\hline \hline Tratamento & $\begin{array}{l}\text { \% Mortalidade' } \\
\text { de plantas }\end{array}$ & Controle (\%) \\
\hline Testemunha & $88,67 \mathrm{a}$ & 00,00 \\
CBPN (Pseudomonas sp) & $61,10 \mathrm{a}$ & 27,57 \\
Benomil & $53,50 \mathrm{ab}$ & 35,17 \\
5-PEP (Bacillus subtilis) & $44,20 \mathrm{abc}$ & 44,47 \\
St BARB (Pseudomonas putida) & $11,00 \mathrm{bc}$ & 77,67 \\
OG (Bacillus subtilis) & $00,00 \mathrm{c}$ & 100,00 \\
\hline
\end{tabular}

$\mathrm{CV}(\%)$

${ }^{1}$ Média de três repetições. Médias seguidas dả mesma letra não diferem entre si pclo teste de Tukey a $5 \%$.

Antagonismo in vivo: Serão mostrados apenas os dados do segundo ensaio de controle biológico onde as plantas foram inoculadas com as rizobactérias por imersão das raizes na suspensão do inóculo, visto que as bactérias se comportaram de modo semelhante quanto ao potencial de controle. A TABELA 2 apresenta os resultados obtidos, onde o isolado OG, isolada do rizoplano de feijoeiro controlou, em $100 \%$, a podridão radicular causada por Fusarium solani, apesar desse tratamento não ter diferido dos tratamentos com as bactérias St. Bárb. (Pseudomonas putida) e 5 Pep. (Bacillus subtilis) Verifica-se, no entanto, que o controle com benomil foi inferior ao Bacillus sp. Já a bactéria St. Barb mostrou grande potencial de biocontrole, uma vez que esta bactéria também apresenta-se como promissora na promoção do crescimento de plantas.
Muitos trabalhos suportam o grande potencial de espécies de Bacillus no controle de patógenos do solo especialmente espécies de Fusarium (FILIPPI et al, 1987; JENNY \& GROSSEMBACHER, 1963 MICHAEL \& NELSON, 1972): Alguns isolados de Bacillus sp. produzem peptídios ácidos com atividade antibiótica (LIEVENS et al.,' 1989).

Promoçāo do crescimento de plantas de pepino: Com relação à promoção de crescimento, verificou-se um aumento, tanto no peso seco de parte aérea como de raiz (TABELA 3), quando as plântulas foram inoculadas com as bactérias $O G$, St. $\mathrm{B}^{\circ} \mathrm{RB}$. e CBPN, não havendo diferença estatística entre elas. A bactéria $5 \mathrm{PEP}$, isolada de pepino, não diferiu do controle tanto no peso seco da parte aérea como de raiz. Os efeitos das bactérias foram mais 
TABELA 3. Efeito de Rizobactérias no Desenvolvimento de Plantas de Pepino, em condições de casa de vegetação.

\begin{tabular}{lcc}
\hline \hline & \multicolumn{2}{c}{ Médias $^{i}$} \\
\cline { 2 - 3 } Tratamentos & $\begin{array}{c}\text { Peso Seco de Parte Aérea } \\
\text { (gramas) }\end{array}$ & $\begin{array}{c}\text { Peso Seco de Raiz } \\
\text { (gramas) }\end{array}$ \\
\hline OG (Bacillus subtilis) & $1,56 \mathrm{a}$ & $0,58 \mathrm{a}$ \\
St. BARB (Pseudomonas sp) & $1,54 \mathrm{a}$ & $0,37 \mathrm{ab}$ \\
CBPN (Pseudomonas sp.) & $1,17 \mathrm{ab}$ & $0,42 \mathrm{ab}$ \\
Controle & $0,91 \mathrm{bc}$ & $0,25 \mathrm{~b}$ \\
5-PEP (Bacillus subtilis) & $0,41 \mathrm{c}$ & $0,21 \mathrm{~b}$ \\
\hline CV(\%) & 17,82 & 22,12 \\
\hline \hline
\end{tabular}

${ }^{\prime}$ Média de três repetições. Médias seguidas pela mesma letra não diferem entre si pelo teste de Tukey a $5 \%$.

evidentes na promoção de crescimento da parte aérea, havendo nitida discriminação entre elas.

Segundo alguns autores, a promoção do crescimento de plantas por rizobactérias se dá pela elıminação dos microrganismos deletérios da rizosfera, fazendo com que a planta cresça com um sistema radicular sadio. Esta eliminação pode se dar pelo mecanismo da antibiose (BROADBENT et al, 1971; CUBETA et al., 1985; UTKHEDE \& RAHE, 1983). Nesse sentido, as Pseudomonas fuorescentes podem atuar no controle biológico e na promoção do crescimento das plantas, pela produção de sideróforos do tipo pseudobactéria capazes de quelar o $\mathrm{Fe}^{3+}$ livre na rizosfera, tornando este micronutriente indisponível para o crescimento dos microrganismos (KLOEPPER et al, 1980; SCHER, 1986). As linhagens St. BARB e CBPN (Pseudomonas sp.) que têm promovido o crescimento de plantas de tomate (MANTOVANELO \& MELO, 1991) vem neste trabalho, comprovar o seu efeito benéfico na promoção do crescimento em pepino (TABELA 3). Urge avaliar seus efeitos na produção de frutos. Bacillus subtilis, $O G$, isolada do rizoplano de feijoeiro na região de Guaíra, SP, tem demonstrado como potente antagonista contra alguns patógenos de raízes de feijoeiro, como $F$. solani f. sp. phaseoli, Sclerotinia sclerotiorum e Rhizoctonia solani.

Neste estudo, embora preliminar, vislumbra-se o potencial de utilização de rizobactérias no tratamento de sementes ou mudas de pepino para controle de $F$. solani em condições de estufa.

Sci. agric., Piracicaba, 52(2):326-330, mai./ago. 1995

\section{REFERENCIA BIBLIOGRÁFICAS}

ALDRICH, J.; BAKER, R. Biological control of Fusarium roseum $\mathrm{f}$.sp. dianthi by Bacillus subtilss. Plant Disease, Reporter, Washington, v. 54, p.446-448, 1970.

BROADBENT, P; BAKER, F.; WATERWORTH, J. Bacterial and actinomycetes antagonistic to fungal root pathogens in Australia Melbournee soil. Australian Joumal of Biological Science, Melbourne, V.24, p.925-944, 1971.

CUBETA, M.A.; HARTMAN, G.L.; SINCLAIR, J.B. Interaction between Bacillus subtılss and fungi associated with soybeen seeds. PlantDisease, St. Paul, v.69, p.506-509, 1985.

FILIPPI, C., BAGNOLI, G.; VOLTERRANI, M.; PICCIG. Antagonistic effects of soil bacteria on Fusarium oxysporum f. sp. dianth. Plant and soll,Dordrecht, v.98, p.161-167, 1987.

JENNY, H.; GROSSEMBACHER, K. Root soil boundry zones as seen in the electron microscope. Soll Science Society of American Proceedings, An Arbor, v. 27, p.273-277, 1963.

KLOEPPER, J.W.; LEONG, J.; TEINTZE, M., SCHROTH, M.N. Pseudomonas siderophores: a mechanism explaining disease suppressive soil. Current Microbiol: New York, V.4; 317-320, 1980.

KOTHS, J.S.; GUNNER, H.B. Establishment of a rhizosphere microflora on camation as a means of plant protection in steamed greenhouse soils. Proceedings of the Americam Society Horticultural Science. v.91, p.617-626, 1967. 
LIEVENS, K. H.; RIJSBERGEN, R.V.; LEYNS, R.F; LAMBENT, B.J.; TENNING, P.; SWINGS, J.; JOOS, H.J.P. Dominant Rhizosphere Bacteria as a Source for Antigungal Agents.Pesticide Science, London, v.27, p.141-154, 1989.

MANTOVAnELO, C.M.; MELO, I.S. Plant Growth Promoting Rhizobacteria on tomato. In: International Plant Protection Congress, 12., Rio de Janeiro, 1991. Abstracts.Rio de Janeiro, 1991.

MELO, I.S. Potencialidades de utilização de Trıchoderma spp. no controle biológico de doenças de plantas. In: Bettiol, W. Controle Biológico de Doenças de Plantas. Campinas: EMBRAPA/CNPDA, 1991. p. 135-156.

MICHAEL, A. H.; NELSON, P.E. Antagonistic Effect of Soil Bacteria on Fusarium roseum "Culmorum" from Carnation. Phytopathology 62: Lancaster, v. 62, p.1052-1056, 1972.
NAIR, N.G., FAHY. P.C. Bacterial antagonistic to Pseudomonas tolaasii and their control of brown blotch ot the cultivars mushroom Agarius bisporus. Reading, Joumal of Applihed Bacteriology, v.35, p.439-442, 1972

ROBBS, C.F. Bactérias como agentes de controle biológico de fitopatógenos. In: Bettiol, W. Controle Biológico de Doenças de Plantas, Campinas: EMBRAPA/CNPDA, 1991. p.121-133.

SCHER, F.M. Biological control of Fusarium wilts by Pseudomonas putida and its enhancement by EDDHA. In: IRON, Siderophores and Plant Disease. London: Plenum, 1986. p. 109-117.

STEVENSON, I.L. Antibiotic activity of actinomycetes in soil and their controlling effects on root-rot of wheat. Jounal General Microbiology, reading, v.14 p.440-448, 1956.

UTKHEDE, R.S.; RAHE, J.E. Interactions of antagonistics and pathogens in biological control of onion white rot. Phytopathology, Lancaster, v.73 p.890-893, 1983.

Recebido para publicação em 15.02 .95

Aceito para publicação em 25.08 .95 